\title{
TENDÊNCIA(S) DAS MONOGRAFIAS DO CURSO DE LICENCIATURA EM GEOGRAFIA
}

\section{Trend(s) of monographies of the licentiateship course on geography}

\author{
Gilmar Alves Trindade ${ }^{1}$
}

\begin{abstract}
RESUMO
Este artigo apresenta os resultados de um estudo acerca das monografias para conclusão do Curso de Licenciatura em Geografia da UESC/BA, entre 1997 e 2004. Objetivamente a realização da pesquisa apontou os seguintes resultados: a maior parte das monografias produzidas pelos graduandos em Geografia insere-se mais nos domínios do bacharelado que da licenciatura; as questões teórico-metodológicas próprias da Geografia são negligenciadas pela maior parte dos autores dos trabalhos; há inconsistência na aplicação dos conceitos básicos da Geografia (espaço, território, paisagem, região e lugar) e a representação cartográfica pode ser considerada insuficiente na maior parte dos trabalhos. Tais resultados indicam que o curso de Geografia precisa programar urgentemente algumas ações a fim de corrigir esses problemas, na medida em que se constatou que entre os trabalhos monográficos apresentados naquele período $76 \%$ deles têm feição de bacharelado, apesar de produzidos em um curso de licenciatura.
\end{abstract}

Palavras-chave: monografias; ensino; pesquisa; licenciatura em Geografia.

\begin{abstract}
This article presents the results of a study concerning monographies written at the end of the Geography major at UESC/BA, between 1997 and 2004. The execution of the survey showed the following results: most of monographies produced by Geography majors at UESC are in the areas of the bachelorship more than in the licensing course; the theoretical-methodological issues specific to Geography are neglected by most of monographies' authors; there is an inconsistency when applying the basic concepts of Geography (space, territory, landscape, region and place) and the cartographic representation can be considered insufficient in most of monographies. These results indicate that the Geography course needs to take urgent actions to correct these problems, as it turned out that among the monographies presented at that time $76 \%$ of them are related to bachelorship feature, although they were produced in a licensing course.
\end{abstract}

Keywords: monographies; teaching; research; geography licensing.

1 Universidade Estadual de Santa Cruz - UESC. Universidade Federal de Sergipe - UFS. Doutorando em Geografia. E-mail: ga.trindade@uol.com.br. 
TRINDADE, G. A. Tendência(s) das Monografias do Curso de Licenciatura em Geografia

\section{TENDÊNCIA(S) DAS MONOGRAFIAS DO CURSO DE LICENCIATURA EM GEOGRAFIA}

Há que se pensar em um ensino que forme o aluno do ponto de vista reflexivo, flexível, crítico e criativo. Não é uma formação para o mercado de trabalho apenas, mas um jovem preparado para enfrentar as transformações cada vez mais céleres que certamente virão.

Nídia Nacib Pontuschka pela inexpressiva presença de professores e alunos do curso nos momentos finais de apresentação dos trabalhos; e na escala nacional, em virtude da escassez de estudos e da pouca visibilidade alcançada por temas dessa natureza nos encontros e congressos de Geografia.

Como há esta lacuna de conhecimento e simultaneamente a necessidade urgente de se ter acesso a essas informações sistematizadas, esperamos ter conseguido reunir neste trabalho alguns elementos que possibilitem conhecer os resultados das monografias e que revelem a pertinência desses trabalhos, no bojo das atividades que articulam a educação superior à educação básica, no caso mais específico do Ensino de Geografia.

Este artigo remete a um projeto de pesquisa desenvolvido na UESC - Universidade Estadual de Santa Cruz / Bahia, acerca dos resultados das monografias apresentadas para conclusão do Curso de Licenciatura em Geografia desta Instituição, com início em outubro/2005 e conclusão em março/2008. Os objetivos fundamentais do trabalho foram:

- Identificar quais têm sido as linhas de abordagens e os temas de pesquisa privilegiados;

- Identificar como está sendo tratada a questão do inter-relacionamento entre Geografia Física e Humana;

- Verificar como tem sido tratada a questão do ensino de Geografia;

- Verificar se os trabalhos têm conseguido apresentar resultados sob uma perspectiva efetivamente geográfica, no sentido da necessária instrumentalização dos conceitos-chave da Geografia (Espaço, Região, Paisagem, Território e Lugar).

Para atender a esses objetivos foram analisadas as monografias apresentadas entre 1997 - 2004, pelo corpo discente do curso de Geografia. Trata-se de um estudo explicativo fundado na análise documental que foi desenvolvida com base no estabelecimento de critérios / categorias teórico-conceituais para a análise.

Embora a exigência de apresentação de uma monografia, para obtenção do título de licenciado em Geografia, não seja tão recente, na maior parte das Instituições de ensino superior no Brasil, sabe-se muito pouco acerca dos resultados gerais desses trabalhos apresentados pelos alunos ao final do curso. A socialização desse expediente não tem ocorrido, efetivamente, por uma série de razões; na escala local, principalmente
A universidade em geral e os cursos de licenciatura em particular têm um papel relevante no contexto da educação brasileira contemporânea, na medida em que a educação superior forma profissionais das diferentes áreas que irão atuar com as disciplinas escolares no ensino fundamental e médio.

Conforme Pontuschka (1999, p. 132), o conhecimento produzido na Universidade, fundado em pesquisa de campo e de laboratório e em pesquisa bibliográfica, deve ser dominado pelo graduado a fim de constituirse em instrumental teórico a ser elaborado, aplicado e recriado para transformar-se em saber escolar.

No caso específico da Licenciatura em Geografia, inúmeras atividades são realizadas no decorrer dos quatro anos que a graduação exige: aulas teóricas e práticas, estágio supervisionado no Ensino Fundamental e Médio, participação em eventos científicos e construção de monografias, entre outras; todas elas amparadas em pesquisa bibliográfica e pesquisa de campo. O objetivo precípuo de todas essas atividades é que os egressos consigam de fato compreender os fundamentos do campo específico da Geografia e suas interfaces com outras áreas do conhecimento, a fim de que possam realizar com competência a transposição didática no momento em que forem atuar na educação básica.

É inegável a importância da construção das monografias no bojo desse processo. Produzindo uma monografia o graduando deve mostrar-se competente na produção do texto em sua língua de origem, deve demonstrar compreender e dominar os fundamentos teórico-metodológicos próprios da Ciência geográfica,

\section{A ARTICULAÇÃO NECESSÁRIA (E TANTAS VEZES MINIMIZADA) ENTRE A UNIVERSIDADE E A EDUCAÇÃO BÁSICA}


TRINDADE, G. A. Tendência(s) das Monografias do Curso de Licenciatura em Geografia

além de entender a aplicação que seu trabalho pode ter no campo específico do ensino e/ou da pesquisa em Geografia.

A monografia constitui-se em atividade obrigatória integrante do currículo da maior parte dos cursos de Licenciatura em Geografia no Brasil, e tem por finalidade proporcionar ao estudante iniciação na pesquisa. O período do estágio supervisionado na educação básica e a apresentação da monografia, nos últimos semestres da integralização curricular, são certamente os dois momentos mais contundentes do curso, não só por serem sínteses de tudo o que foi feito no decorrer do processo, mas especialmente por tratarem-se das atividades que os aproximarão efetivamente da inserção no mercado de trabalho. Na avaliação de Callai (2003, p. 71), a pesquisa passa a ser uma possibilidade concreta na construção do conhecimento e na formação de sujeitos autônomos que possuam a autoria de seu pensamento.

De acordo com Silva e Caetano (2003, p. 282), "o educador deve ter cada vez mais a consciência de que também é um produtor de conhecimento", posto que este não seja produzido apenas em laboratório, mas também em sala de aula e na pesquisa direcionada ao ensino. Concordamos com o fato de que "um país incapaz de gerar suas próprias ideias está fadado a ser um país dependente" (SANTOS, 1999, p. 5); esta assertiva é válida também para o professor/educador, que não deve estar sempre submetido ao livro didático no processo de ensino/aprendizagem; deve produzir seu próprio conhecimento e estimular seus alunos para que façam o mesmo. Precisa ser um profissional capaz de compreender os fundamentos teórico-metodológicos da Geografia, da realidade socioespacial do Brasil com suas articulações com as questões mundiais, além de buscar absorver a dimensão pedagógica do seu fazer profissional, na medida em que,

A disciplina escolar Geografia está no jogo dialético entre a realidade da sala de aula e da escola, entre as transformações históricas da produção geográfica na Academia e as várias ações governamentais representadas hoje pelos Pareceres da Educação e Parâmetros Curriculares Nacionais (PONTUSCHKA, 1999, p.111).

O docente precisa dominar o conhecimento geográfico a ser ensinado. Aquele modelo que definia a competência do professor apenas baseando-se no saber acadêmico está superado, uma vez que há a necessidade de outras competências para que ele possa desenvolver com eficácia a sua prática pedagógica (PONTUSCHKA, 1999, p. 131).

A pesquisa em ensino de Geografia é um expe- diente que envolve ainda poucos professores e graduandos dos cursos de licenciatura no Brasil. Geralmente costuma-se privilegiar as questões relacionadas à organização do espaço, que pedem a articulação entre Geografia física e humana, muitas vezes difícil de concretizar no momento da pesquisa. Spósito (2003, p. 32) considera paradoxal que em um país onde o analfabetismo não está erradicado e os indicadores relativos ao nível de conhecimento alcançado no ensino fundamental não têm melhorado efetivamente, dê-se tão pouca importância às pesquisas relativas ao ensino na educação superior e na educação básica. A geógrafa sugere que empreendamos o trabalho de tentar mapear os resultados da pesquisa realizada por alunos e professores da graduação e pós-graduação em Geografia, no Brasil, a fim de que possamos levantar a situação específica do ensino dessa disciplina.

$\mathrm{Na}$ avaliação de Trindade e Oliveira (2003, p. 203) ainda há muito a ser feito no sentido de construir na Universidade um curso que seja de fato contextualizado com a prática que se exerce nos níveis fundamental e médio. Um passo importante, nesse sentido, seria buscar conhecer os resultados dos trabalhos dos graduados em Geografia, tanto no âmbito de suas atividades acadêmicas quanto profissionais, e motivá-los a socializar tais resultados na própria Universidade, nas escolas em que atuam, com a sociedade.

Pesquisa e ensino devem caminhar de fato articuladamente. Alunos e professores devem empreender um esforço no sentido de promover um diálogo profícuo e permanente entre o ensino superior e a educação básica, caso se espere, efetivamente, construir um país mais desenvolvido socialmente, mais justo, mais humano. O papel da Universidade é precioso, na medida em que,

A universidade conserva, memoriza, integra, ritualiza uma herança cultural de saberes, ideias, valores; regenera essa herança ao reexaminá-la, atualizá-la, transmiti-la; gera saberes, ideias e valores que passam, então, a fazer parte da herança (MORIN, 2001, p. 81).

Concordamos com Suertegaray (2002, p. 111) quando discute que se é necessário pensar sobre que educação se quer, que pesquisa se quer, que educação geográfica para professores se quer, faz-se necessário pensar em educar professores a partir e com a pesquisa. Trata-se de uma pesquisa efetivamente contextualizada com o ensino dessa disciplina e com a educação escolar de um modo geral.

No caso específico deste estudo alguns dos 
TRINDADE, G. A. Tendência(s) das Monografias do Curso de Licenciatura em Geografia

questionamentos que buscamos responder com a realização da pesquisa foram: que tipo de análise os alunos do Curso de Geografia têm realizado? Qual a ideia de Geografia que aparece nesses trabalhos? Há contextualização entre pesquisa e ensino de Geografia, entre educação superior e educação básica? Qual a contribuição científica e/ou social desses trabalhos monográficos? Com os dados levantados e analisados criticamente esperamos ter elementos mais concretos para realizar a avaliação dos resultados das monografias apresentadas, compará-los com a realidade de outros cursos de Geografia e discutir com a comunidade geográfica local, regional e nacional acerca dos caminhos e das possibilidades de renovação do ensino e da pesquisa em Geografia no Brasil, atualmente.

\section{EXPLICITANDO CAMINHOS DA METODOLOGIA ESTABELECIDA PARA REALIZAÇÃO DA PESQUISA}

O projeto de pesquisa foi desenvolvido no Campus da UESC (Biblioteca, Colegiado de Geografia, LAHIGE - Laboratório de História e Geografia e gabinete do pesquisador) entre outubro/2005 a março/2008. Para o estudo do tema proposto utilizamos a abordagem qualitativa de pesquisa em educação, que foi complementada com a utilização de dados quantitativos necessários durante seu desenvolvimento. Trata-se de uma pesquisa de caráter exploratório (COSTA, M. A.; COSTA, M. F., 2001), cujo tema ainda não foi suficientemente estudado nas escalas local, regional e nacional. Considerandose a necessidade constante de aprofundamento teórico com relação à temática proposta, iniciamos o trabalho com a revisão de literatura mais aprofundada, realizada em livros, revistas científicas e meios eletrônicos que tratam da discussão acerca das abordagens atuais em torno da pesquisa e do ensino de Geografia no Brasil.

O passo seguinte foi a análise de $100 \%$ das monografias para conclusão do Curso de Licenciatura em Geografia (1997-2004) existentes nos arquivos da Biblioteca/UESC, do LAHIGE e no Colegiado de Geografia. Vale registrar que a exigência para produção de monografia no curso de Geografia desta instituição existe desde 1997 (antes mesmo das deliberações gerais do MEC/SEF), de acordo com regulamentação interna; entretanto, os primeiros trabalhos foram apresentados efetivamente a partir do ano 2000 (ano de conclusão de curso daquela $1^{\text {a }}$ turma de 1997). Dessa forma, analisamos as monografias apresentadas nos anos 2000/2001/2002/2003/2004.

A pesquisa teve um caráter explicativo fundado na análise documental (COSTA, M. A.; COSTA, M. F., 2001, p. 62), onde a abordagem metodológica abarcou as seguintes etapas:

a) Catalogação das monografias;

b) Organização e relação dos dados / conteúdos brutos;

c) Redução / resumo dos conteúdos;

d) Interpretação dos dados utilizando-se das categorias teórico-conceituais estabelecidas;

e) Análise dos resultados.

A fim de aperfeiçoar o processo de análise das informações buscamos categorizar os elementos (BARROS; LEHFELD, 2001, p. 88) de acordo com o estabelecimento dos seguintes referenciais teóricoconceituais:

1. Vinculação teórico-metodológica a uma das correntes do pensamento geográfico (Geografia Tradicional, Quantitativista, Crítica e Humanística). O trabalho vincula-se efetivamente a uma das correntes? Há coerência entre o discurso construído e os pressupostos teóricometodológicos da corrente privilegiada?

2. Tratamento concedido aos conceitos-chave da Geografia (Espaço, Região, Paisagem, Território e Lugar). Quais os Conceitos privilegiados? Realizam tratamento teóricoconceitual? Como se dá? Há pertinência quanto ao enfoque do trabalho?

3. Perspectiva da abordagem geográfica: há articulação efetiva entre Geografia Física e Humana? Como se estabelece na construção do trabalho?

4. Perspectiva da natureza do trabalho no âmbito da abordagem desenvolvida: há ênfase para o ensino de Geografia, privilegiando-se a discussão didático-pedagógica, própria de um curso de Licenciatura; ou a ênfase é dada para a pesquisa de campo desvinculada da discussão didático-pedagógica e mais relacionada a um curso de bacharelado? 
TRINDADE, G. A. Tendência(s) das Monografias do Curso de Licenciatura em Geografia

\section{ANALISANDO ALGUNS RESULTADOS QUE A PESQUISA REVELOU}

A análise das monografias apontou alguns resultados que merecem atenção por parte dos corpos docente e discente do Curso de Licenciatura em Geografia. Inicialmente podemos afirmar que são poucos os alunos que realmente dominam as dimensões teóricometodológicas próprias da Geografia; verificamos que da maior parte dos trabalhos o que emerge é um tratamento superficial e até mesmo equivocado quanto à aplicação dos conceitos e categorias geográficas.

A dimensão da análise espacial é tratada superficialmente na maior parte dos trabalhos; são poucos os autores que de fato analisam o espaço geográfico, matéria-prima fundamental no campo da Geografia. A representação da paisagem é negligenciada por muitos dos autores dessas monografias, é como se o campo visual de suas observações não emitisse nenhuma mensagem a ser trabalhada cognitivamente no momento de transcreverem os resultados da pesquisa desenvolvida.
Na formação do raciocínio geográfico,

o conceito de paisagem aparece, no meu entendimento, no primeiro nível de análise do lugar, estando estreitamente ligado com esse conceito. É pela paisagem, vista em seus determinantes e em suas dimensões, que se vivencia empiricamente um primeiro nível de identificação com o lugar (CAVALCANTI, 1998, p.100).

Quanto à representação cartográfica, podemos afirmar que a maior parte dos trabalhos faz uma análise espacial que não consegue demonstrar através de mapas, plantas, croquis e outros recursos, as características do espaço estudado na monografia; são poucos os trabalhos que trazem representações cartográficas dignas de serem apresentadas como produtos de uma conclusão de curso em Geografia. As análises sintetizadas dos 60 trabalhos monográficos selecionados nos dão uma ideia do conjunto e simultaneamente nos permitem identificar os poucos trabalhos que podem

TABELA 1 - VÍNCULO TEÓRICO-METODOLÓGICO

\begin{tabular}{|c|c|c|}
\hline Corrente do Pensamento Geográfico & Quant. & (\%) \\
\hline Geografia Crítica & 25 & 41,67 \\
\hline Geografia Tradicional & 16 & 26,67 \\
\hline Geografia Humanística & 1 & 1,67 \\
\hline Geografia Quantitativa & 0 & 0,00 \\
\hline Nenhum e/ou indefinido & 18 & 30,00 \\
\hline Totais & 60 & 100 \\
\hline
\end{tabular}

ser considerados efetivamente geográficos e que têm alguma relevância social e/ ou científica.

Os resultados demonstraram que entre as 60 monografias analisadas prevalecem as abordagens fundamentadas na Geografia Crítica. Isso não significa necessariamente que seus autores construíram um discurso de análise espacial com coerência teóricometodológica na instrumentalização de categorias e conceitos amiúde presentes na dialética marxista; ao invés disso, a maior parte dos trabalhos tenta apresentar uma análise crítica em torno dos temas selecionados para pesquisa, fazendo uso de referências bibliográficas de geógrafos - especialmente brasileiros - historicamente associados à Geografia Crítica. São bastante frequentes as citações de autores como Milton Santos, Roberto Lobato Corrêa, Ana Fani Alessandri Carlos, Arlete Moysés Rodrigues e Marcelo Lopes de Souza. Na realidade o que emerge da maior parte dos trabalhos é uma tentativa que os graduandos fazem de fortalecer seus argumentos utilizando-se do suporte encontrado nas palavras destes e de outros geógrafos. Na verdade eles reproduzem uma prática de construção do conheci- 
mento comum entre muitos membros da universidade; entretanto, em determinados trabalhos, as citações exageradas parecem preencher os espaços onde os autores não foram capazes de desenvolver seu próprio pensamento, sua explicação para a realidade encontrada com a pesquisa.

Quanto aos trabalhos identificados como vinculados à Geografia Tradicional, que corresponderam a $26,7 \%$ do total, são caracterizados mesmo por uma análise descritiva de determinados fenômenos relacionados à dinâmica da natureza, frequentemente dissociada da ação humana e/ou do uso que a sociedade faz dos mesmos. Na maior parte desses trabalhos aparecem referências a autores da Geologia, da Hidrologia e mesmo da Oceanografia; no entanto, a inter-relação sociedade/natureza efetivamente não é considerada na discussão. Alguns desses trabalhos são desenvol- vidos por um viés que pode ser considerado como de educação ambiental, mas pecam pelo distanciamento que mantêm da Geografia, na medida em que muito remotamente fazem uso dos conceitos e categorias geográficas, além de não privilegiarem geógrafos que frequentemente discutem a interação entre o físico e o humano em Geografia, como Aziz Ab'Saber, Dirce Suertegaray e Francisco Mendonça, entre outros.

A Geografia Teórico-quantitativista e a Geografia Humanística foram consideradas muito vagamente pelos autores das monografias. Poucas referências são feitas aos geógrafos humanistas e o quantitativismo surge somente nas representações estatísticas em forma de gráficos e tabelas, mas apenas como uma representação matemática dos dados coletados em campo, e não como referência teórico-metodológica que tenha norteado o trabalho. Chama a atenção o fato de que entre os 60

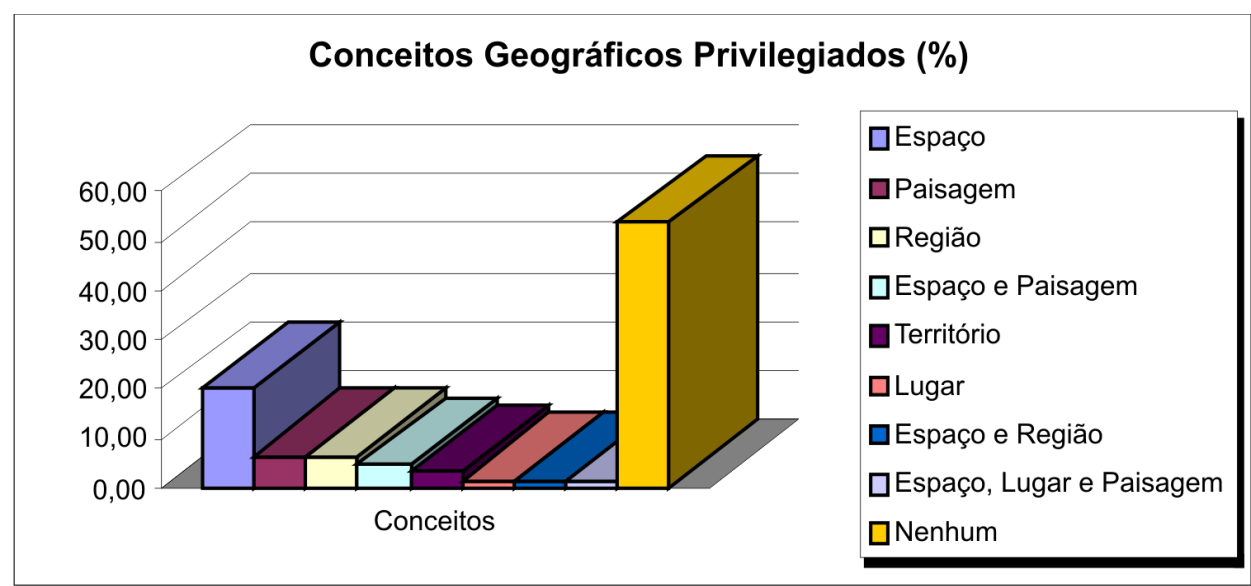

FIGURA 1 - CONCEITOS GEOGRÁFICOS PRIVILEGIADOS NAS MONOGRAFIAS

trabalhos analisados, em $30 \%$ deles não encontramos vínculo algum com nenhuma corrente do pensamento geográfico. Em outras palavras, o que foi constatado é que em $30 \%$ deles nada há efetivamente de Geografia.

Os conceitos são formulados para explicar fenômenos e situações que existem de fato na realidade. O uso dos conceitos, de forma contextualizada, dá mais clareza àquilo que se pretende explicar. A instrumentalização de conceitos e categorias científicas é imprescindível na construção do conhecimento nas diferentes áreas. Por isso existe nos mapas curriculares de diferentes cursos um espaço indispensável para as disciplinas vinculadas às questões epistemológicas. No caso específico do curso de Geografia da UESC/ BA essas disciplinas são: História do Pensamento Geográfico e Conceitos Básicos da Geografia. Contudo, não podemos cometer o equívoco de imaginar que apenas nestas duas disciplinas é que a aplicação dos conceitos e categorias geográficas deve acontecer. Esta instrumentalização deve ocorrer ao longo de todo o curso de Geografia, na maior parte das disciplinas do mapa curricular; neste sentido, o uso dos conceitos geográficos deve ser estimulado pelos professores do curso, especialmente pelos geógrafos.

No momento de realização do estágio supervisionado e da produção da monografia, especialmente, faz-se necessário uma atenção redobrada por parte dos orientadores dessas atividades, acerca de como os alunos estão fazendo uso desses conceitos articulados aos seus temas de pesquisa e às suas atividades didático-pedagógicas.

Consideramos que

a ciência geográfica é viabilizada através da explicação das interrelações existentes entre a sociedade e a natureza, responsáveis pela produção/reprodução do espaço geográfico. Para que possam dar conta dessa 
explicação os geógrafos fazem uso de cinco conceitos essenciais à análise geográfica: espaço, região, paisagem, território e lugar, sem os quais, pode-se dizer, não há Geografia (TRINDADE, 2003, p.147).

Dessa forma, ao analisarmos a figura 1, nos surpreendemos com a constatação de que em $53 \%$ das monografias (32 em um total de 60 ), nenhum dos conceitos geográficos é de fato utilizado pelos autores ao longo de todo o desenvolvimento dos trabalhos. Há absurdos como ao invés de usarem o conceito de paisagem, os alunos optarem por panorama, visual, vista parcial ou aspecto; ou ainda quando deixam de usar o conceito de espaço, tão caro ao conhecimento geográfico, para fazer uso de termos como ambiente, local ou área. Grande parte dos autores das monografias parece ter esquecido que

como toda ciência, a Geografia possui alguns conceitos-chave, capazes de sintetizarem a sua objetivação, isto é, o ângulo específico com que a sociedade é analisada. Como ciência social a Geografia é objetivada via cinco conceitos-chave que guardam entre si forte grau de parentesco, pois todos se referem à ação humana modelando a superfície terrestre: paisagem, região, espaço, lugar e território (CORREA, 1995, p.16).
Entre os trabalhos em que os autores tiveram o cuidado de pensar e desenvolver seus temas de pesquisa amparados nos conceitos da Geografia aparece o uso do conceito de espaço (em $20 \%$ deles), paisagem (em 7\%), região (em 7\%), território (em 3\%) e lugar (em $2 \%$ deles). Em alguns trabalhos há o uso simultâneo de vários conceitos.

Precisamos refletir acerca desses resultados e buscar caminhos que fortaleçam a dimensão de geograficidade de nossas práticas, professores e alunos, envolvidos com o ensino dessa disciplina. Na Geografia que se produz atualmente no Brasil percebe-se, em muitos trabalhos de pesquisa,

a volta ao empirismo, a recusa do debate teórico que se desdobra e se limita ao plano fenomênico, ou ainda na postura que reduz os problemas atuais a uma possibilidade técnica. A Geografia, às vezes, sucumbe diante da necessidade da não-teorização dos temas de sua alçada, o que revela, a meu ver, um recuo (CARLOS, 2002, p. 177).

Ao discutir sobre a articulação entre pesquisa e ensino, teoria e prática em Geografia, Ruy Moreira considera que uma das razões maiores da inconsistência da relação entre teoria e prática na formação em

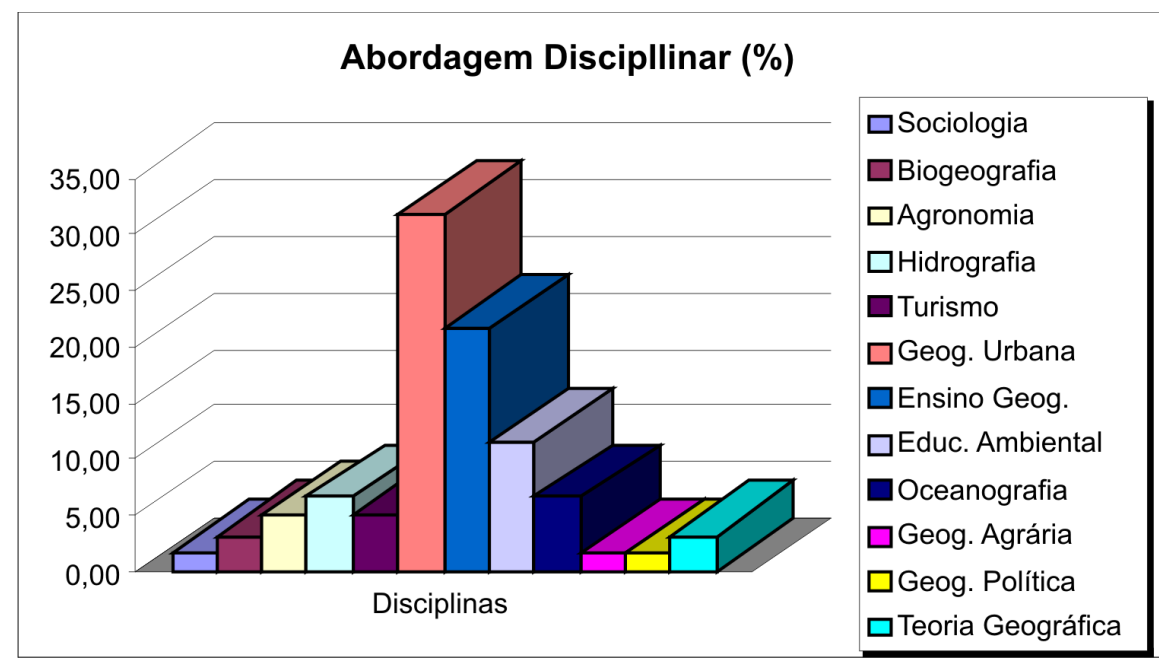

FIGURA 2 - DISCIPLINAS ÀS QUAIS AS MONOGRAFIAS ENCONTRAM-SE VINCULADAS

Geografia é que "a teoria só ganha força de precisão quando orientada na prática da pesquisa e a pesquisa só tem substância prática quando informada na teoria" (MOREIRA, 2003, p. 36). Existe uma série de indagações e inquietações que tais resultados suscitam, mas, necessariamente, o enfrentamento dessa questão por parte dos professores e alunos envolvidos deve acon- tecer o mais imediatamente possível.

Entre os temas definidos para o desenvolvimento de suas monografias, os alunos privilegiaram assuntos relacionados especialmente com a Geografia Urbana (31\%), o Ensino de Geografia (21\%) e a Educação Ambiental (12\%), que, juntos, correspondem a $64 \%$ do total dos trabalhos analisados. Outras abordagens geográficas 
(e não geográficas) aparecem nos demais trabalhos; inclusive monografias que apesar de solicitadas para concessão da Licenciatura em Geografia, têm conteúdos integralmente inseridos nas concepções teórico-metodológicas da Agronomia, do Turismo e da Sociologia. Isso é possível constatar tanto no próprio discurso dos autores quanto nas referências bibliográficas que fundamentaram esses trabalhos; além, ainda, da absoluta ausência de mapas ou qualquer representação cartográfica que expresse a espacialização do objeto de pesquisa.

Ou seja, parece que grande parte desses alunos, após cursarem quatro anos de Geografia, continua desconhecendo que

seja como ciência, seja como matéria de ensino, a Geografia desenvolveu uma linguagem, um corpo

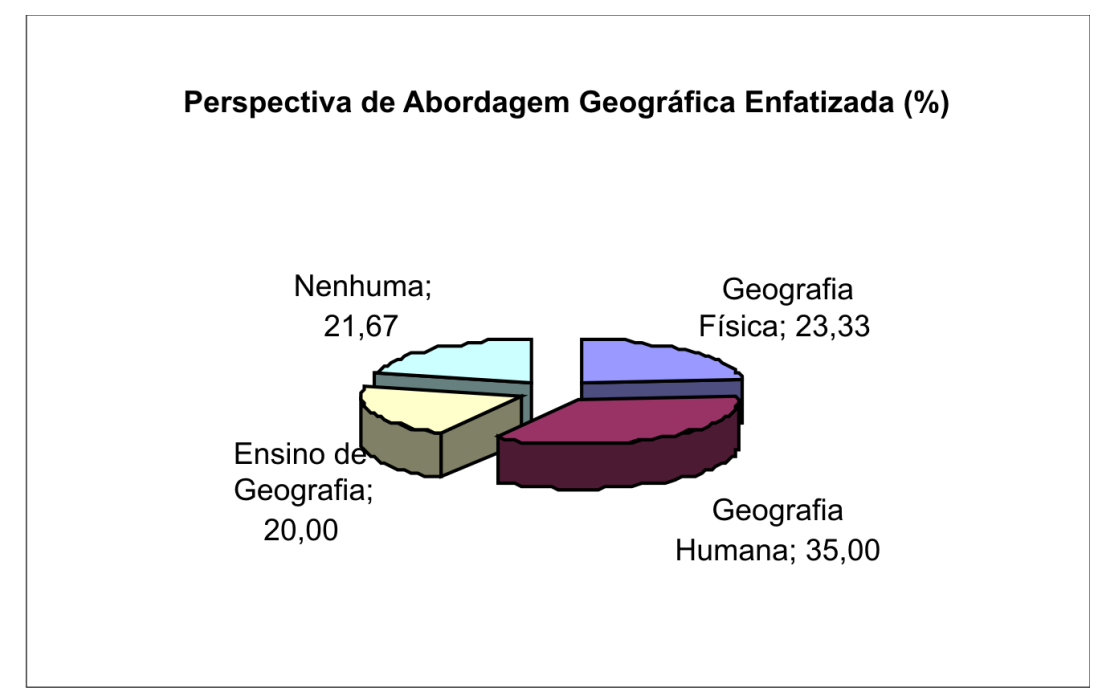

FIGURA 3 - ABORDAGENS GEOGRÁFICAS ENFATIZADAS NAS MONOGRAFIAS

conceitual que acaba por constituir-se numa linguagem geográfica. Essa linguagem está permeada por conceitos que são requisitos para a análise dos fenômenos do ponto de vista geográfico (CAVALCANTI, 1998, p. 88).

Além da instrumentalização dos conceitos geográficos, a representação espacial é um elemento essencial na conclusão de um trabalho em Geografia, pois se faz necessário representar espacialmente o que foi estudado, só assim se estará trabalhando de fato nos domínios da Geografia.

Ao concluir a análise das monografias percebemos que são raros os alunos que conseguem produzir seus trabalhos de conclusão de curso dando-Ihes um tratamento efetivamente geográfico. Trata-se de uma constatação inquietante se consideramos que ao longo dos quatro anos de curso eles têm contato com diferentes professores, com leituras e discussões científicas no âmbito da Geografia que abordam desde as questões epistemológicas ao tratamento dado atualmente às análises geográficas, além de travarem contato com graduandos e professores de Geografia de outras instituições sempre que participam de encontros, simpósios ou congressos na área da Geografia.
Apesar de a análise da figura 3 demonstrar que $35 \%$ das monografias inserem-se no contexto da Geografia Humana e de que $23 \%$ delas no contexto da Geografia Física, isto não quer dizer, necessariamente, que todos os trabalhos conseguem realizar o inter-relacionamento entre os elementos da natureza e a ação humana no momento de analisar a organização espacial; a maior parte dos alunos não considera que "o espaço geográfico deve ser considerado como algo que participa igualmente da condição do social e do físico, um misto, um híbrido" (SANTOS, 1999, p. 70).

Na realidade, na maior parte dos trabalhos, sejam eles de natureza da Geografia Física ou Humana, não se percebe a preocupação em construir esse interrelacionamento, mas apenas em abordar determinados temas que ora tendem para disciplinas do curso tradicionalmente associadas à Geografia Física e ora tendem para disciplinas associadas à Geografia Humana; é como se a maior parte dos alunos não conseguisse compreender o espaço geográfico como fruto da intervenção humana sobre a natureza ao longo do tempo, transformando os elementos físicos em paisagens geográficas humanizadas. A maior parte dos trabalhos parece desconsiderar que 
existe uma relação necessária, dialética, entre sociedade e espaço; é a ação humana consciente que transforma a natureza em espaço geográfico e ao produzi-lo, produz o homem e as relações com os outros homens (CARLOS, 1997, p. 16).

Após a análise dessas monografias produzidas por alunos do curso de Geografia somos levados a concordar plenamente com Gonçalves, quando afirma que

a crítica de que os cursos de Geografia têm sido pouco práticos, como alguns vêm fazendo, não quer dizer que esses mesmos cursos têm sido pouco práticos porque têm sido muito teóricos. Sustentamos exatamente a tese contrária: os cursos de Geografia têm sido pouco práticos porque têm sido pouco consistentes teoricamente (GONÇALVES, 1999, p. 83).

Impressiona o fato de que não somente entre os alunos, mas que também entre muitos professores dos cursos de Geografia, existe uma recusa em ler e discutir os clássicos do pensamento geográfico. Alguns consideram essas leituras complexas, difíceis, até mesmo monótonas e entediantes. São poucos os professores que estimulam a reflexão e o debate em torno das ideias de Humboldt, Kant, Hettner, La Blache, Ratzel, Ritter, Hartshorne, para citar apenas alguns dos que nos antecederam e que são importantes para o entendimento da Geografia que se faz atualmente.

\section{A LICENCIATURA EM GEOGRAFIA NEGLIGENCIA A SUA DIMENSÃO DIDÁTICO-PEDAGÓGICA}

Chegamos enfim à preocupação precípua que norteou o projeto de pesquisa: qual é mesmo a tendência que emerge das monografias orientadas pelos professores e produzidas pelos alunos, ao final do curso de licenciatura em Geografia? Os trabalhos

têm dado ênfase às questões relacionadas ao ensino e aprendizagem em Geografia na educação básica ou têm demonstrado o interesse do corpo discente (e também docente?) por temas que, apesar de articulados ao conhecimento geográfico, não atendem aos reais

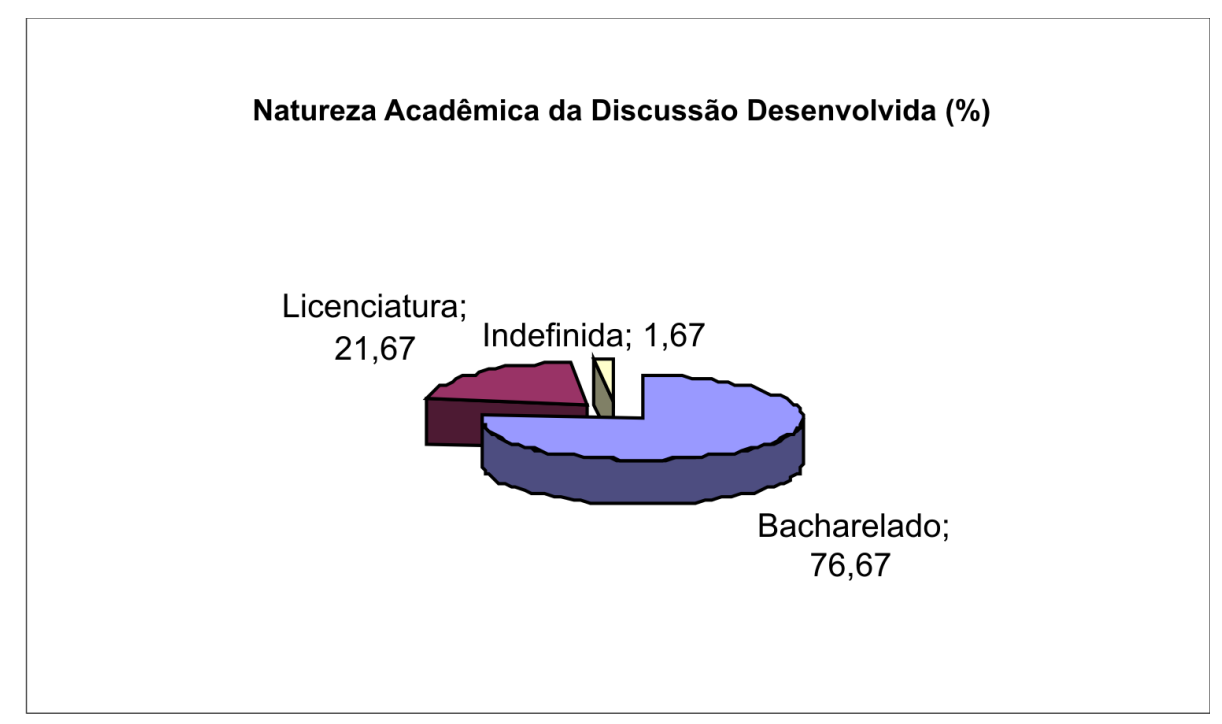

FIGURA 4 - NATUREZA ACADÊMICA DA DISCUSSÃO DESENVOLVIDA NAS MONOGRAFIAS

objetivos estabelecidos para um curso de licenciatura em Geografia?

A constatação de que $76 \%$ das monografias têm viés de bacharelado (Figura 4) é de fato preocupante, se consideramos que foram construídas em um curso de licenciatura. O que pode explicar o porquê desses 
resultados? Questões e problemas internos que dizem respeito ao curso de Geografia ou questões gerais, mais amplas, relacionadas ao contexto atual da educação brasileira, especialmente aquelas que dizem respeito às condições de trabalho do professor na escola pública?

Grande parte dos vestibulandos tem chegado mal preparada na universidade. Há deficiências graves quanto à compreensão, interpretação e produção de textos em língua portuguesa. São poucos os alunos que no $1^{\circ}$ ano do curso conseguem atender as pré-condições mínimas esperadas para um universitário: faltam proficiência em língua portuguesa e os conhecimentos geográficos básicos necessários para dar prosseguimento ao curso. O comportamento heterônomo da maioria deles impede que assumam com responsabilidade a condição de alunos do ensino superior. Muitos reclamam das leituras mais aprofundadas exigidas pelas disciplinas "epistemológicas"; outros declaram não compreenderem os textos, e assim, ao invés de buscarem vencer as deficiências, abandonam as leituras ou leem o texto pela metade. Textos e artigos em outros idiomas, como inglês e até mesmo espanhol, uma língua latina, não são incorporados às suas rotinas como graduandos em uma universidade. A maior parte dos alunos lê apenas os livros e textos solicitados pelos professores, são raros os alunos que têm a autonomia de buscarem por si sós as leituras que ampliarão seus conhecimentos.

Por outro lado, devemos também considerar o papel dos professores que atuam no curso, se de fato contribuem para melhorar a sua qualidade ou se são corresponsáveis pelas deficiências e problemas que, apesar de detectados já há algum tempo, continuam aparecendo nos momentos de os alunos apresentarem os resultados de seus trabalhos monográficos e de suas práticas de ensino durante o estágio supervisionado. Como os professores enxergam a estrutura curricular do curso? Como se sentem atuando em um curso com as especificidades da licenciatura? Que tipo de Geografia fazem e que tipo de Geografia exteriorizam em sala de aula e nas aulas de campo, com seus alunos? Como os professores geógrafos tratam a própria dimensão geográfica, a interdisciplinaridade e a dimensão pedagógica da Geografia? Como os não geógrafos abordam a questão geográfica na interface com as disciplinas em que atuam? Como transportam conteúdos acadêmicos, muitas vezes compartimentados, para uma linguagem didático-pedagógica necessária para alunos que atuarão como profissionais da educação básica? E como o colegiado e/ou departamento de curso atuam no sentido de acompanharem o desenvolvimento do trabalho dos professores e sua adequação ao currículo do curso?
Parece ser inegável que parte dos professores sente-se desconfortável em atuar em uma licenciatura. Mas o que explica este fato, principalmente quando se trata de professores concursados para vagas específicas na licenciatura? Poderíamos questionar por que alguns alunos prestam vestibular para um curso de licenciatura, mesmo declarando-se sem nenhuma vocação para o magistério. Da mesma forma, é intrigante saber que há professores concursados para a licenciatura que não "se sentem bem" atuando em um curso de formação de professores. Ingressaram na universidade pela possibilidade de fazer pesquisa e muitos secundarizam as atividades de ensino. É preciso refletir sobre o fato de que

não é simplesmente o professor que precisa ser, também, pesquisador, mas é igualmente o técnico que precisa se pedagogizar, isto é, saber fazer a mediação de saberes, o que é característico, entre outros, de profissionais da educação (GONÇALVES, 1999, p.82).

De acordo com Abreu (2003, p. 8), outro problema apontado e bastante discutido é que existe certo "descompromisso" no interior dos departamentos e colegiados de Geografia quanto à formação do professor, que acaba sendo uma tarefa dos professores de prática de ensino e das chamadas disciplinas pedagógicas, de forma que as demais disciplinas dariam conta da formação do geógrafo, ou melhor dizendo, da formação geográfica. Isso parece ser mesmo verdadeiro, na medida em que constatamos que em algumas disciplinas são tratados apenas os conteúdos "técnicos" específicos, sem a preocupação de realizar a transposição didática entre os conteúdos acadêmicos e a forma de abordálos na educação básica. Certamente por isso mesmo é que "persiste ainda uma brutal diferença entre a Geografia que se ensina no $1^{\circ}$ e $2^{\circ}$ graus, e aquela que se ensina no nível superior" (SANTOS; BERNARDES, 1999, p. 20).

Esse desencontro entre teoria e prática só vem reforçar a ideia de que é preciso uma articulação maior entre a formação que se realiza na universidade com a prática de ensino na educação básica. Tudo está a indicar que

a escola que temos encontra-se distante do que propõem as análises, e a desqualificação profissional do professorado é notória, porque os cursos de formação não vêm acompanhando as mudanças (LIBÂNEO, 2006, p. 49).

O Estado, responsável pela elaboração das políticas públicas para a educação, a universidade e a 
sociedade brasileira como um todo, precisam atentar para o fato de que:

As universidades formam mal os futuros professores, os professores formam mal os alunos. Poucas universidades brasileiras têm uma política definida em relação à formação de professores para o ensino fundamental e médio. Há um desinteresse geral dos institutos e faculdades pelas licenciaturas. Com isso, os professores saem despreparados para o exercício da profissão, com um nível de cultura geral e de informação extremamente baixo, o que resulta num segmento de profissionais sem as competências pessoais e profissionais para enfrentar as mudanças gerais que estão ocorrendo na sociedade contemporânea (LIBÂNEO, 2006, p. 91).

De acordo com Braga (2005, p. 10), a formação dos licenciados em Geografia pode ser considerada como insuficiente para capacitar um profissional que dê conta de responder, não a uma prática disciplinar, de gavetas, mas a um projeto de educação com uma sólida base teórico-conceitual; a autora considera que especialmente a formação docente no campo dos conteúdos pedagógicos está muito longe de se aproximar do que seria minimamente desejável. Precisamos, portanto, assumir com coragem essas constatações que os resultados da pesquisa vão revelando:

- Por que muitos de nossos alunos continuam desinteressados pela dimensão pedagógica da Geografia, mesmo tendo prestado vestibular para um curso de Licenciatura?

- Qual tem sido o papel do currículo no sentido de orientar a prática pedagógica dos professores envolvidos com o curso?

- Quais ações devem ser desenvolvidas pelo Colegiado de curso e pelo Departamento, a fim de fortalecer a dimensão pedagógica da Licenciatura em Geografia?

- Qual a responsabilidade do corpo docente (individual e coletivamente) ao se constatar que entre os trabalhos de conclusão de curso apresentados entre 2000 e 2004, 76\% deles não traz nenhuma preocupação com a questão do ensino de Geografia?

- Quais providências podem ser tomadas pelo Colegiado de Curso e/ou pelo departamento para que essa realidade seja transformada?

Estas e outras questões devem nos acompanhar a partir de então. O primeiro passo deve ser socializar os resultados da pesquisa com professores e alunos diretamente envolvidos, buscando uma reflexão profunda acerca de qual tipo de profissionais somos e sobre qual tipo de profissionais queremos ajudar a formar. $\mathrm{O}$ que implica em refletir sobre como tem sido o nosso envolvimento com o ensino de Geografia que se produz na universidade e sua (des)articulação com a geografia escolar. Em um segundo momento, esperamos ser possível estabelecer o diálogo com professores e alunos da licenciatura em Geografia de outros lugares do Brasil, que provavelmente vivem experiências semelhantes.

Se grande parte dos nossos alunos, graduados em licenciatura em Geografia, saem da universidade com ideias imprecisas acerca da aplicação dos conhecimentos adquiridos ao longo do curso, com vagueza teórico-metodológica e com muitas dúvidas sobre como instrumentalizar esses conhecimentos nas aulas de Geografia na Educação Básica, isso indica que o curso necessita urgentemente passar por uma grande transformação, pois,

Na formação inicial, nos cursos universitários, conside-
ro necessário que seja garantido aos alunos o direito
de conhecer as diferentes concepções sobre a ciência
geográfica, de participar da reflexão sobre o papel pe-
dagógico da Geografia, para que compreendam que a
presença da Geografia na escola não é neutra, não é
gratuita; ao contrário, ele deve estar presente na escola
com propósitos políticos e pedagógicos bem definidos
e conscientes (CAVALCANTI, 2002, p. 113).

Ou seja, os alunos podem até estar adquirindo uma gama importante de conteúdos da Geografia e áreas afins em grande parte das disciplinas do curso; pode haver sim comprometimento e responsabilidade da maior parte dos professores quanto ao trabalho com os conhecimentos específicos das disciplinas que lecionam; entretanto, ao longo do processo de ensinoaprendizagem existe algum problema que está impedindo que a maior parte dos alunos conclua o curso tendo plena consciência do que seja a ciência geográfica e de como seus conhecimentos devem ser trabalhados na Educação Básica.

É importante registrar que cerca de $30 \%$ das monografias apresentam qualidade e relevância científica e social, especialmente por considerarem a articulação necessária entre teoria e prática em Geografia quando enfatizam sua dimensão pedagógica. Além disso, também é importante considerar que há trabalhos que podemos chamar "monografias municipais" que trazem contribuições interessantes para os municípios de origem dos alunos do curso, principalmente porque contêm mapas e plantas que foram construídos ou adaptados 
pelos próprios alunos e informações geográficas e de outras naturezas que servirão como fonte de consulta para o município (acreditamos que os autores das monografias enviem cópias dos trabalhos para as bibliotecas do município onde a pesquisa foi desenvolvida).

Apesar disso, porém, não podemos aceitar que apenas cerca de $30 \%$ dos alunos graduados no curso respondam satisfatoriamente ao que a Geografia e a sociedade esperam deles: que sejam profissionais competentes na área de sua formação, que tenham consciência do seu papel social enquanto professores de Geografia e que contribuam com a produção de um conhecimento geográfico relevante e com sentido para a vida das pessoas. Pois, como escrevemos recentemente, ainda

tem sido recorrente a prática de estudos geográficos descritivos e descontextualizados, onde crianças e jovens são levados a estudarem um conteúdo amorfo e completamente desvinculado de suas experiências cotidianas; como se não fizessem parte da sociedade, dos lugares, do mundo (TRINDADE, 2003, p. 148).

\section{CONSIDERAÇÕES FINAIS}

Sabemos que há fatores endógenos e exógenos que comprometem a qualidade do ensino tanto na universidade quanto na educação básica. Entre eles, a desvalorização dos profissionais da educação em uma sociedade que valoriza cada vez mais, por um lado, o técnico, o engenheiro, os profissionais do marketing, e por outro lado, as celebridades instantâneas, o jogador de futebol e os modelos, "personagens" que frequentemente constroem fortunas meteóricas e geralmente não têm um discurso muito positivo acerca da escola - entre aqueles que a frequentaram. Evidentemente que em uma sociedade capitalista tal desvalorização é refletida imediatamente nos baixos salários que os professores recebem, geralmente pagos por uma carga de trabalho desumana, além do desrespeito a que são submetidos com muita frequência pelas secretarias municipais e estaduais de educação. Tudo isso deve mexer com a cabeça dos jovens - muitos deles quase adolescentes, eis outro problema - que ingressam nos cursos de licenciatura; ainda mais quando se constata que:

Não são apenas os professores da rede pública que estão perdendo o interesse pelo magistério ou deixando a profissão. Também nas universidades os pesquisadores que se dedicavam ao estudo de questões do ensino e da sala de aula estão preferindo temas mais gerais [...] a desvalorização econômica e social do magistério, além de comprometer o status social da profissão, também retira o status acadêmico dos campos de conhecimentos que lhe correspondem, tornando o ensino uma linha de pesquisa menos nobre. Não é casual, por exemplo, a pouca valorização dos cursos de licenciaturas nas universidades e a insuficiência de pesquisas nesse campo (LIBÂNEO, 2006, p. 93).

Nada impede que um professor - geógrafo ou não - que atua em um curso de licenciatura em Geografia, também realize pesquisas dissociadas da dimensão pedagógica; entretanto, simultaneamente, o que se espera desse profissional é que seja capaz de, em algum momento, abrir-se para a reflexão, o diálogo e a produção do conhecimento que articule as especificidades de sua área do saber - as disciplinas do currículo - com as necessidades e objetivos do curso do qual é parte integrante. Podemos considerar que em muitos dos trabalhos monográficos analisados, a influência do professor-orientador foi decisiva na escolha dos alunos pelos temas mais voltados a uma concepção de bacharelado em Geografia que de licenciatura.

O curso de licenciatura em Geografia da UESC/ $\mathrm{BA}$, onde a pesquisa foi desenvolvida, elaborou recentemente e implantou a partir de 2004 um novo currículo; durante o processo de elaboração muitos impasses surgiram, pois se trata de um trabalho complexo que envolve atores sociais que possuem visões de mundo e de Geografia diferentes; apesar disso alguns avanços, ainda que tímidos, emergiram ali, especialmente pela incorporação de 15 horas de aulas de prática de ensino inseridas em quase totalidade das disciplinas do mapa curricular. Alguns professores já realizavam essa prática anteriormente à regulamentação; outros professores não entenderam, a princípio, como incorporariam essa prática de ensino no bojo das atividades teóricas, mas esforçaram-se em respeitar o que foi deliberado coletivamente através do novo currículo; entretanto, infelizmente, também houve casos de alguns professores que se recusaram decisivamente em inserir a prática de ensino em suas disciplinas. Por isso, até já apontamos anteriormente que:

A supervalorização do bacharelado em detrimento da licenciatura tenta impor-se, no discurso e na prática de alguns profissionais que mesmo atuando em cursos com as especificidades das licenciaturas, insistem em realizar um trabalho desvinculado das reais necessidades de alunos que em pouco tempo estarão em sala de aula no ensino fundamental e médio (TRINDADE; OLIVEIRA, 2003, p. 203).

Consideramos que cabe agora ao Colegiado de curso, composto por professores e alunos, fazer cumprir 
TRINDADE, G. A. Tendência(s) das Monografias do Curso de Licenciatura em Geografia

as determinações do novo currículo. Mais que isso, cabe aos professores, que tenham sensibilidade em assumir que atuam em um curso de licenciatura e que, portanto, têm o dever ético e moral de realizar suas atividades pedagógicas em consonância com o perfil do curso em que atuam, respeitando os alunos e demais colegas professores que estão na licenciatura em Geografia por opção de estudo, trabalho e vida.

Acreditamos que produzindo e socializando pesquisas como esta contribuímos com o "mapeamento" das tendências dos cursos de Licenciatura em Geografia no Brasil, neste momento. Além disso, esperamos compartilhar angústias e esperanças com aqueles que têm preocupações semelhantes e que desejam uma formação geográfica mais consistente na relação teoria / prática, comprometida com uma educação de qualidade e atenta às questões gerais da sociedade da qual somos parte integrante. Devemos continuar questionando:

Quais os caminhos pelos quais a Geografia poderá se inserir no exame crítico de nossa época? Que geógrafos queremos formar? Sem essas reflexões poderemos aceitar, sem perceber, um profissionalismo estrito, preocupado com um saber do aqui e do agora, submisso a modelos educacionais hegemônicos (SANTOS; BERNARDES, 1999, p. 5).

Esperamos que os resultados da pesquisa contribuam com a discussão e reflexão em torno das questões relacionadas aos cursos de licenciatura em Geografia no Brasil e de sua articulação com a educação básica. Que outros trabalhos sejam realizados para ampliação desta temática e para levantamento de novos dados para análise, pois somente assim seremos capazes de resolver os problemas encontrados e de construir uma formação geográfica mais sólida, dialógica e comprometida com a excelência profissional.

\section{REFERÊNCIAS}

ABREU, S. de. Geógrafo: bacharel - licenciado: pensando a (de) formação geográfica. In: ENG/Fala Professor, 5., 2003, Presidente Prudente - SP. Anais... 20 a 24 Jul. 2003. p. 7-11.

BARRos, A. P.; LeHFEld, N. S. Projeto de Pesquisa: propostas metodológicas. 12. ed. Petrópolis: Vozes, 2001. $128 p$.

BRAGA, R. B. Formação inicial de professores: uma trajetória com permanências eivada por dissensos e impasses. AGB Nacional. 13 p. Disponível em: <www.cibergeo.org/agbnacional/ terra_livre/Braga.html>. Acesso em: 26/10/2005.

CALLAI, H. Do Ensinar Geografia ao produzir o pensamento geográfico. In: REGO, Nelson et al. (Orgs.). Um pouco do mundo cabe nas mãos: geografizando em educação o local e o global. Porto Alegre: Editora da UFRGS, 2003. p. 57-73.

CARLOS, A. F. A. Espaço e Indústria. 7. ed. São Paulo: Contexto, 1997. 70 p.

A Geografia brasileira, hoje: algumas reflexões. Revista Terra Livre, AGB/São Paulo, n. 18. p. 161-178, jan./ jun. 2002.

CAVALCANTI, L. S. Geografia, Escola e construção de conhecimentos. Campinas/SP: Papirus, 1998. 192 p. 2002. $127 \mathrm{p}$.

Geografia e práticas de ensino. Goiânia: Alternativa,

COLEGIADO DE GEOGRAFIA. Regulamentação da Monografia. Ilhéus: UESC, 1997.

CORREA, R. L. Espaço: um conceito-chave da Geografia. In: CASTRO, I. E. et al. (Orgs.). Geografia Conceitos e Temas. Rio de Janeiro: Bertrand Brasil, 1995. p. 15-47.

COSTA, M. A; CostA, M. F. Metodologia da Pesquisa: Conceitos e Técnicas. Rio de Janeiro: Interciência, 2001. $136 \mathrm{p}$.

GONÇALVES, C. W. P. Reformas no mundo da educação, reformas no mundo. In: CARLOS, A. F. A. et al. (Orgs.). Reformas no mundo da educação: parâmetros curriculares e Geografia. São Paulo: Contexto, 1999. p. 68-87.

LIBÂNEO, J. C. Adeus professor, adeus professora? Novas exigências educacionais e profissão docente. 9. ed. São Paulo: Cortez, 2006. 104 p.

MOREIRA, R. O que talvez ainda esteja faltando. In: ENG/ Fala Professor, 5. 2003, Presidente Prudente - SP. Anais... 20 a 24 Jul. 2003. p. 34-40.

MORIN, E. A Cabeça bem-feita: repensar a reforma, reformar o pensamento. 3. ed. Rio de Janeiro: Bertrand Brasil, 2001. $128 p$.

PONTUSCHKA, N. N. A Geografia: pesquisa e ensino. In: CARLOS, Ana Fani Alessandri (Org.). Novos Caminhos da Geografia. São Paulo: Contexto, 1999. p. 111-142.

SANTOS, M. A natureza do espaço: técnica e tempo, razão e emoção. 3. ed. São Paulo: Hucitec, 1999. 308p.

SANTOS, M.; BERNARDES, A. Tarefas da Geografia brasileira num mundo em transformação: um momento de sua trajetória. Revista Ciência Geográfica, AGB/Bauru, v. 13. p. 4-22. maio/ago. 1999.

SILVA, C. N.; CAETANO, V. S. O ensino público, ensino de Geografia e o contexto acadêmico. Revista Ciência Geográfica, Bauru/SP: AGB, v. 9, p. 281-283, set./dez. 2003.

SPOSITO, M. E. Pesquisa e Ensino em Geografia: desafios e perspectivas. Fala Professor. Presidente Prudente/SP: AGB, p. 22-33. 2003. 
TRINDADE, G. A. Tendência(s) das Monografias do Curso de Licenciatura em Geografia

SUERTEGARAY, D. M. Pesquisa e Educação de professores. In: PONTUSCHKA, Nidia Nacib et al. (Orgs). Geografia em Perspectiva. São Paulo: Contexto, 2002. p. 109-114.

TRINDADE, G. A. (Re)pensando a instrumentalização do conceito de Lugar no âmbito da Geografia. Revista Ciência Geográfica, AGB/Bauru, v. IX, n. 2, p. 146-152, maio/ago. 2003.

TRINDADE, G. A.; OLIVEIRA, C. G. Geografia: reflexões sobre ensino e currículo. In: ENPEG, 7., 2003, Vitória. Anais... UFES, 14 a 18 set. 2003. p. 198-204. 